\title{
GIS TOOL TO OPTIMIZE ROUTE PLANNING TO IMPROVE ENERGY EFFICIENCY OF MOTOR VEHICLES IN SRI LANKA
}

\author{
S.A Silva and J.M.S.J. Bandara* \\ Department of Civil Engineering, University of Moratuwa, Sri Lanka \\ bandaras@sltnet.lk*
}

\begin{abstract}
Transportation has become a vital part of economic development of a country. Poor transportation planning and management is not only waste valuable time but also wastes lot of energy and creates unnecessary air pollution. In recent years, Sri Lanka also has experienced a high growth rate in urban population and the number of private vehicles. Most evident feature of such a trend is urban road congestion. Most of the main roads and local roads in some urban areas are facing unexpectedly high traffic flows which cause time waste in transit, environmental pollution and huge losses to the economy of the country. Therefore, efficient route planning has become one of an important study area because governments also have identified that build new roads is not the only solution for the traffic congestion problem.

One of the main reasons for traffic congestion is that concentration of vehicles to selected few roads, may be due to shorter length or may be due to their condition. In optimum route planning, it is essential that to identify alternative routes available to connect different origins and destinations that can be used to divert the traffic from congested road links. However, the number of vehicles that can be diverted will depend on the condition of the road links, existing traffic level and also the land use pattern along the routes. This implies that if the routes are planned well and assign traffic accordingly it will help to minimize the congestion on a road network.

The objective o

handle national road network in Sri Lanka. The model is capable of determining the minimum distance or minimum time/cost path between any two node pairs and determining alternate paths avoiding any or all nodes or links between any selected node pair. The model is capable of estimating the traffic flows on road links if the travel demand between the node pair is known. Model is capable of approximately estimating the emission level on road links in addition to the travel time. Moreover, the model has the features of changing the level of operation of a road by using different adjustment factors by considering the road conditions and land use pattern. This facilitate the designers to plan the road network in an efficient manner that will help to minimize the traffic congestion by identifying the routes which should improved or vehicles should or should not be diverted.
\end{abstract}

Key words: GIS, Energy efficiency, Optimum route planning, Traffic assignment

\section{INTRODUCTION}

High traffic congestion is a serious problem facing the road transportation infrastructure not only in Sri Lanka but also in most part of the world. The congested roads in a road network waste lot of fuel energy and valuable time of people. It is believed that one of the reasons for this problem is bad management of existing road network. Furthermore, congested roads of a zone are good indication of air pollution level and inefficiency of route planning in that area. Therefore, the efficient route planning has become one of an important study area.

\section{OBJECTIVE OF THE STUDY}

The objective this paper is to present

Visual Basic (VB 6) to handle national road network in Sri Lanka. Model helps to plan the roads in an 
optimum way which will help to reduce emission levels of zones and to save fuel energy of vehicles. Model has following capabilities.

1.Manage the road network data

2.Find the alternative paths and best paths

3.Monitor Emission level

4.Manage the accident data

5.Estimate the traffic flows

\section{EFFECT OF BAD ROUTE PLANNING}

The ever increasing number of vehicles on the roads has created higher demand for road space in urban cities. Therefore, plan and manage the existing road network in an efficient manner is an immense responsibility of road engineers because new road construction will not be a good answer for this problem.

One of the main problem can be caused by bad traffic planning is high traffic congestion. Traffic congestion is a serious problem facing the road transportation infrastructure in many parts of the world. Traffic delays and congestion are major source of inefficiency, wasted fuel, and commuter frustration. Measuring and identifying localities of these delays, and assigning traffic effectively, is an important step towards reducing the time spend on congested traffic.

operate without moving in a traffic congestion can be defined as idle time of a vehicle. Idle time not only reduces vehicle engine efficiency but also wastes lot of fuel energy. Figure 1 shows the vehicles fuel efficiency with the idle time of trucks using GPS data.

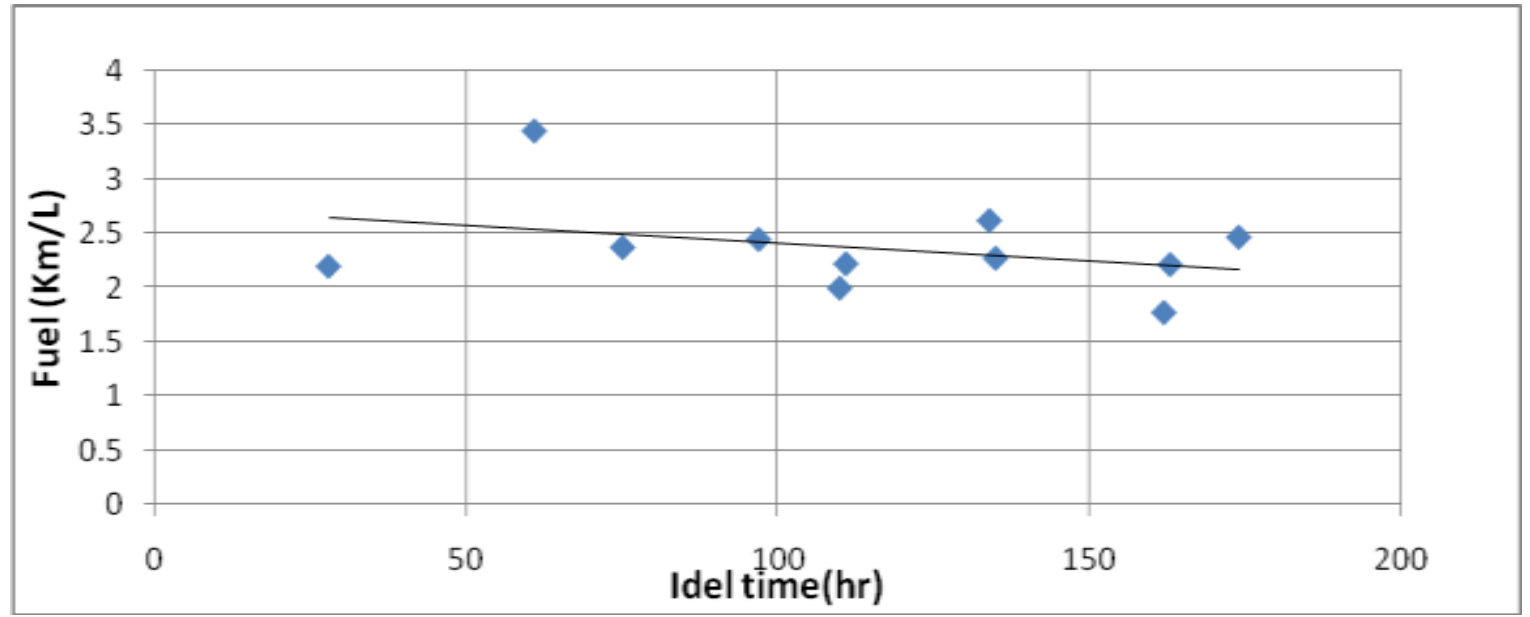

Source: Fleet management using GIS and GPS, Silva S.A, Bandara J.M.S.J, 2009

Figure 1:

Several studies also have shown that roadway congestion is continuing to get worse. For example, the Texas Transportation Institute (TTI) conducts an Urban Mobility Study that includes estimates of traffic congestion in many large cities and the impact on society. The study defines congestion as 


\section{ALTERNATIVE PATHS}

The simple definition for the alternative path is next best path which is available to travel between two nodes. There are two main types of alternative paths, which are,

1.Link independent path

2.Node independent path

Above two types of alternative paths are shown in figure 2.

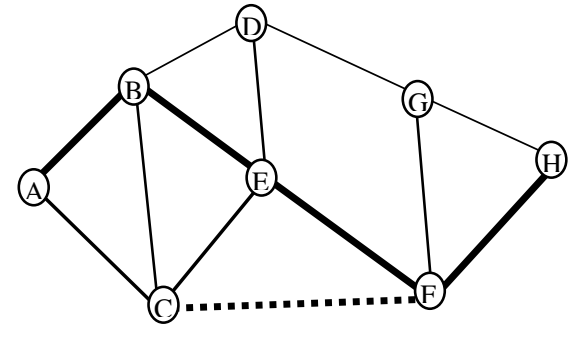

- Link independent path

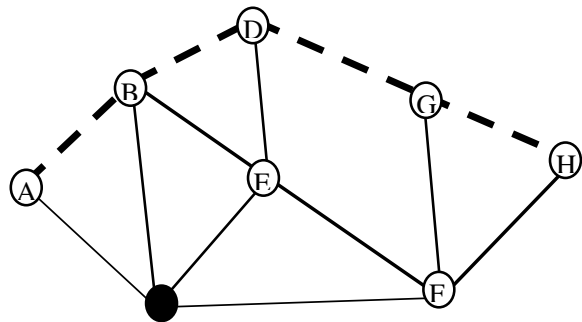

- - Node independent path

Figure 2: Different Alternative Path Arrangements

\subsection{LINK INDEPENDENT PATHS}

next the best path that will not use any of the links

links (barrier links) along the best path cannot be used. However, it is acceptable to go through the junctions which, are on either side of the barrier link or links. Finding link independent paths are important in situations where certain stretches of road are unusable as a result of road renovation, flooding, high traffic congestion etc. In the case of traffic congestion in a particular link, the congestion can be minimized by finding an alternative route.

the alternative path by assigning a high cost value to the link or links at the beginning of the best path computation. This will find the best paths which will not go through prohibited (closed) links of the network.

\subsection{NODE INDEPENDENT PATH}

best path which is not permitted to go through

one or more nodes will be restricted and not all the nodes. Node independent path is important in situations such as accidents, public meetings, flooding, etc at a junction because traffic congestion due to above reasons can be minimized by finding an alternative route that avoid such location. The main feature of the node independent path is route cannot access the road links which connects to the

values to links which connects to the barrier node or nodes.

\subsection{IMPORTANCE OF ALTERNATIVE PATHS}

Alternative paths are very useful for engineers and urban planners because it provides lot of information to them for their planning and operations. Node and link independent paths help to manage the traffic well when traffic is congested due to poor road conditions, high traffic flow or simply due to bad weather and visibility of the roads. These incidents may close one or more roads links or nodes of the network and at that time alternative paths give solutions to divert the traffic to other road links. 


\subsection{DEVELOPED MODEL TO FIND THE ALTERNATIVE PATHS}

Figure 3 shows the developed model to find out the alternative paths of a given road network. Model can find the shortest paths, node and link independent paths of a network. This model has been developed by customizing ArcGIS network analysis tool using VB 6.0.

Figure 3: Interface of the model developed to find out the alternative path

\section{EMISSION LEVEL AND ENERGY EFFICIENCY}

It is commonly known that as traffic congestion increases, emissions (and in parallel, fuel consumption) also increase. In general, emissions and fuel consumption are very sensitive to the type

-state

velocity will give much lower emissions and fuel consumption compared to a stop-and-go driving pattern [4]. By decreasing stop-and-go driving that is associated with congested traffic, emissions can be reduced. According to above facts, it can be argued that the emission level of a zone is good indication of the efficiency of road network.

\section{EMISSION LEVEL ESTIMATION}

Excessive vehicles cause several environmental problems such as contribution to climatic changes, increasing the number of health problems, etc. Traffic flow and their speed of a road links are the 
To carry out the capacity restrain trip assignment calculations [6] and to estimate the traffic flows, a model is developed using VB 6.0. This model helps to assign the trips to a given road network using available inter zonal flow matrix. The methodology which is used to estimate the traffic flows are shown in Figure 4. Options available in the model are as following.

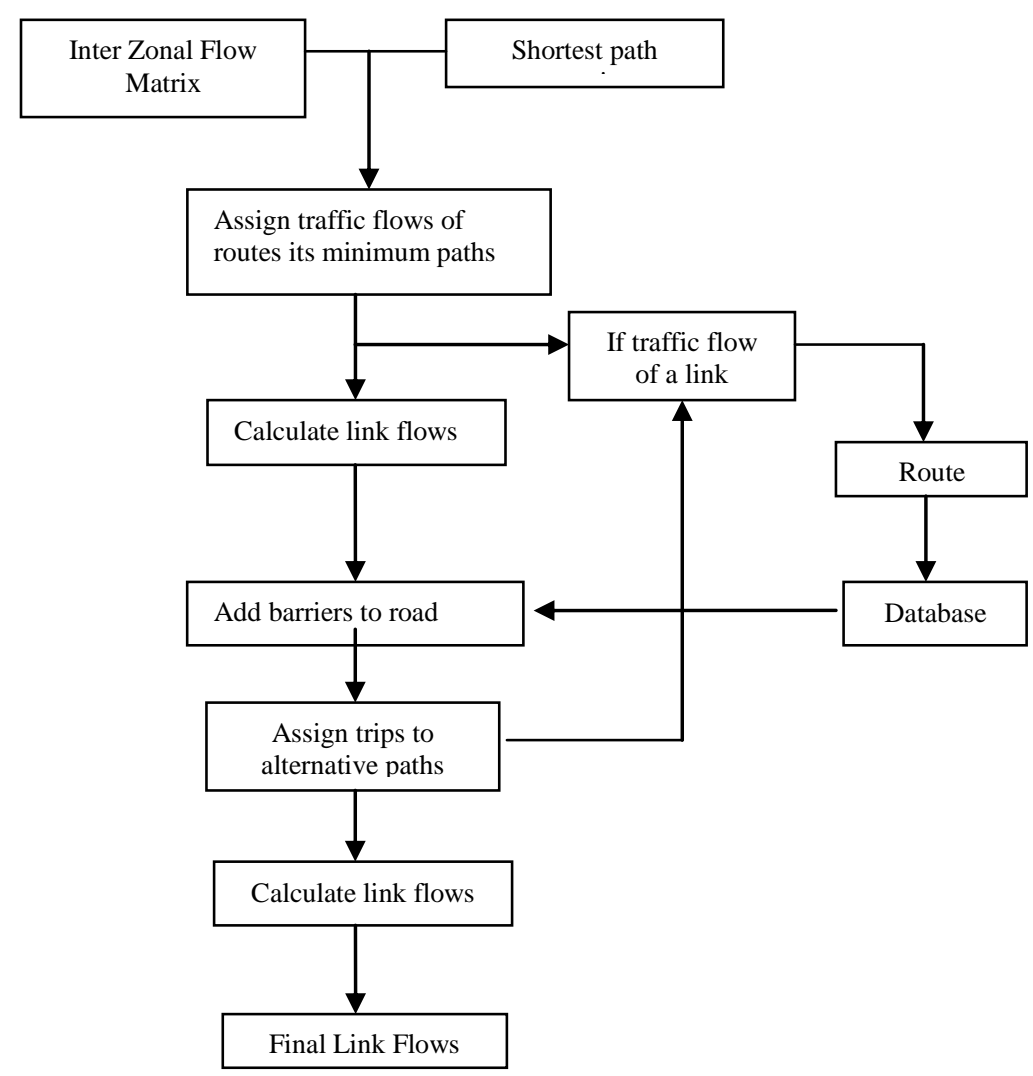

Figure 4: Traffic flow estimation process

To calculate the total trip lengths of vehicles, it is required to find out the total length of the road network. This can be done easily using the intersect analysis tool in ArcGIS because it provides the database of the road links which are in the zone. Using that database and geometry calculation tool in GIS it is possible that to find out the total length of roads in a zone.

Vehicle registration statistics can be found by referring the Department of Motor Traffic data. These data helps to find out the percentages of vehicle fuel type within a zone. Vehicle emission factors one of the main factors, which determine the accuracy of emission inventory. There is a database which is prepared by National Building Research Organization (NBRO). However, there are some shortcomings of that database which may be improved using emission test data available at present.

\subsection{CALCULATE THE EMISSION LEVEL}

to estimate the emission level of a zone.

Emission Level $=V \times L \times P V \times P F \times E F$

$\mathrm{V}=$ Total vehicle flow rate of the zone

$\mathrm{L}=$ Total road length of the zone

$\mathrm{PV}=$ Percentage of vehicle type

$\mathrm{PF}=$ Percentage of vehicle by fuel type 
$\mathrm{EF}=$ Emission factor

\subsection{DEVELOPED MODEL TO ESTIMATE THE EMISSION}

Emission level of any given zone can be found using the above equation. However, in order to manage the required data and do the calculations, it is important to have a model. Because it is difficult to do such calculation process manually. Therefore, in this study, it is attempted to develop a GIS model using above methodology to estimate the emission of DS divisions of Sri Lanka by customizing the ArcGIS. Figure 5 shows the developed model.

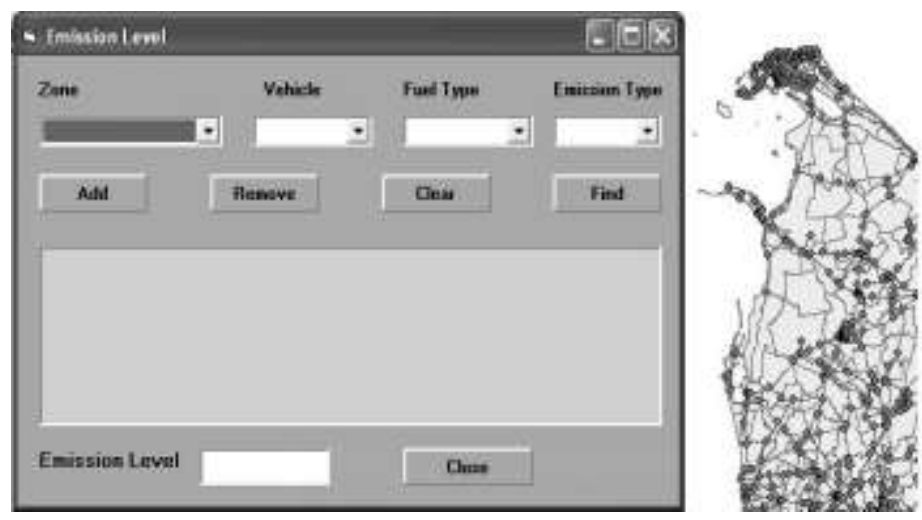

Figure 5: Interface of the developed model for estimate the emission level

\section{CASE STUDY (SOUTHERN PROVINCE)}

To find out the importance of alternative paths to save energy and to reduce the emission level of an area, case study is done in Southern Province. Figure 6 shows the route A002, which has highest traffic flows. However, figure 7 shows that road traffic can be reduced by improving the alternative path which available to go from Ambalangoda to Tangalla. Emission levels were estimated for the two scenarios; with and without improvements to the identified alternate route.
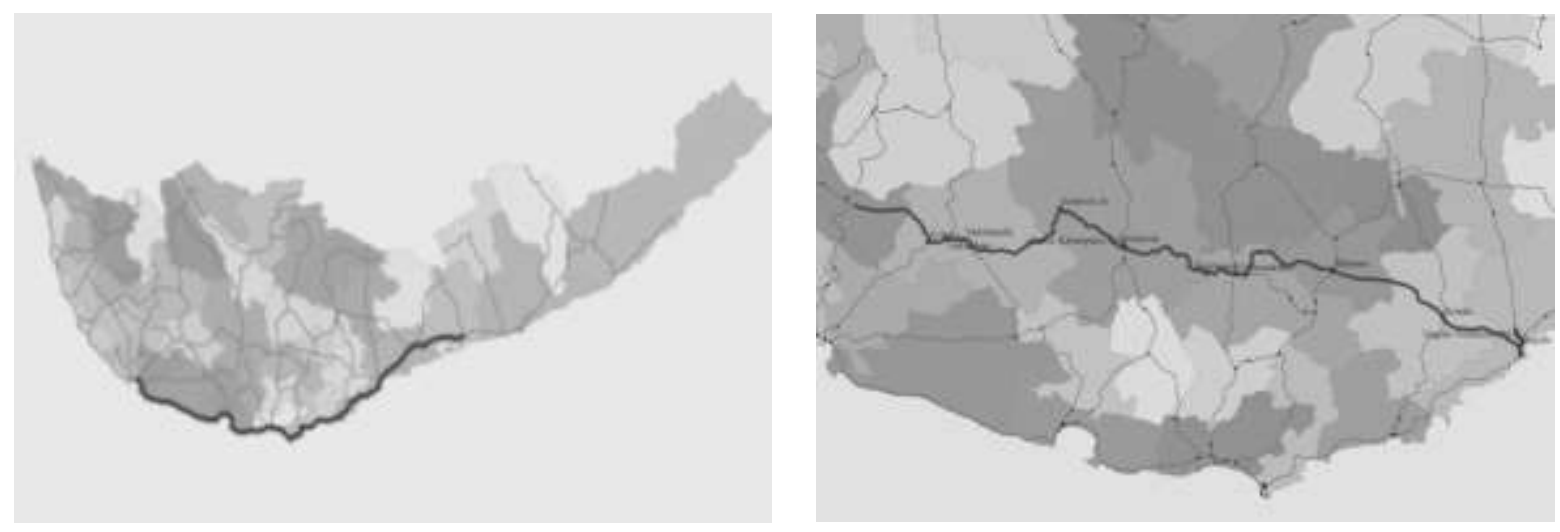

Figure 6: The route which has the highest traffic flow and alternative route

The graph 7 indicates that after improving the alternative path from Ambalangoda to Tangalla emission level of most DS divisions of Southern Province will be reduced because of some vehicles are diverted to the alternative route. This will increase the speed of the roads and decrease the road congestion caused by high traffic flow. However, in this study, zones emission levels are found assuming the all the emission factors are same (i.e. assume constant value). Moreover, the emission level is calculated for unit length of road of a zone. According to the graph, it can be found that model can be effectively used to identify the efficient routes of a region to improve and reduce the emission level to save fuel energy of vehicles. Furthermore, emission factors for different operating speeds are available it is possible to show that further emission level reduction is possible. 


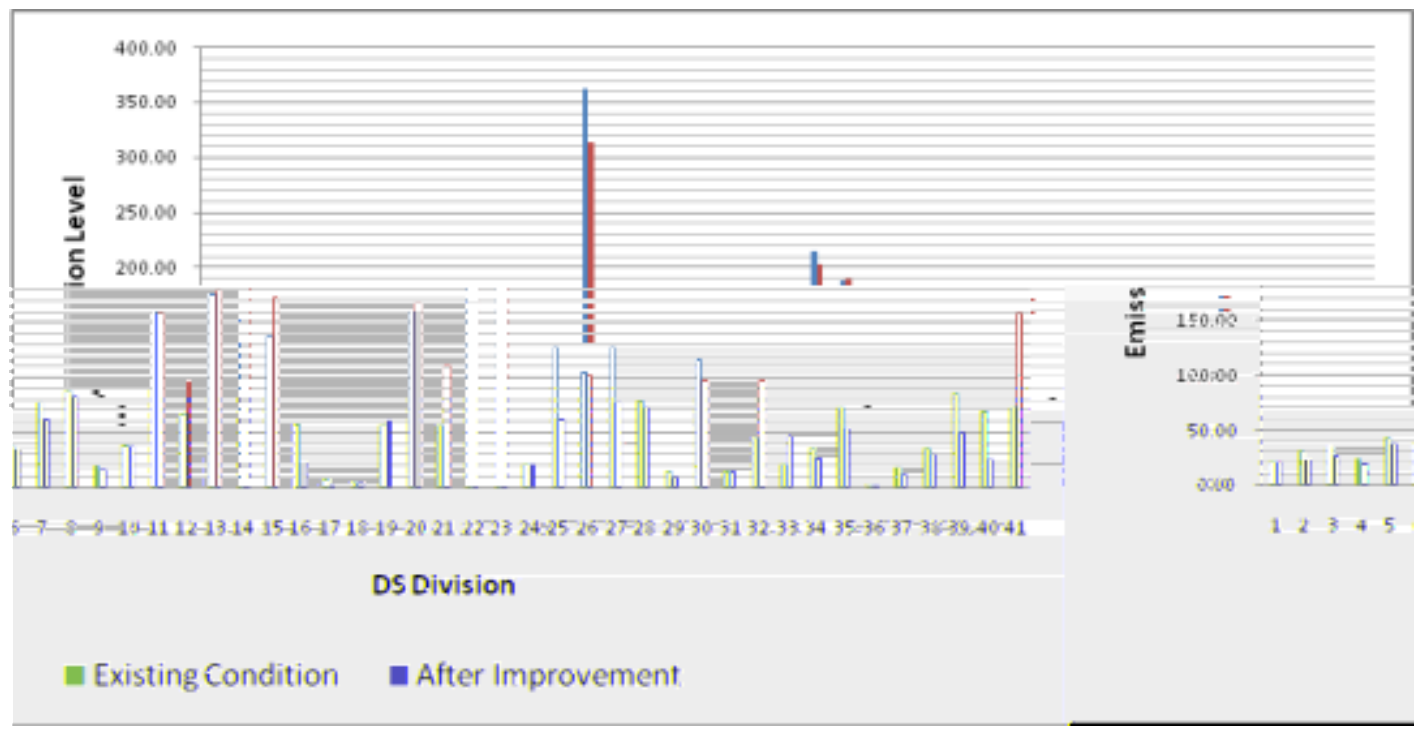

Figure 7: Emission levels of zones in Sothern Province

The estimated emission levels are as follows:

Existing estimation of total emission level in southern province $=3170 \mathrm{k}$

Total estimation level of southern province after improvement $=3047 \mathrm{k}$

Percentage of emission level drop $=\left(\begin{array}{ll}3170 & 3047\end{array}\right) / 3170$

$=4 \%$

$\mathrm{K}=$ constant which is used to represent the emission factor

\section{CONCLUSION}

The case study results show that the developed IHMS is helps to identify routes to be improved to reduce the traffic congestion on road network by distributing the traffic to alternative routes. The reduction of traffic congestion save fuel energy and reduce the air pollution of zones. Therefore, the model can be used to plan the routes in an optimum way to reduce the energy waste which is caused by traffic delays.

However, case study gives emission level estimation at the DS division level and considering National road only. Therefore, model has to be further improved to accommodate provincial roads (Class $\mathrm{C}$ and D) and more realistic emission factors. Furthermore, in this study, alternative paths are found using the link distances but travel time or generalized travel cost could be in future studies.

\section{REFERENCES}

Arvind Thiagarajan, Lenin Ravindranath, Katrina LaCurts, Accurate, Energy-Aware Road Traffic Delay Estimation Using Mobile Phones, Transport Research Board, 2008

Dijkstra, E. W. (1959). "A note on two problems in connexion with graphs"

Matthew Barth, Kanok Boriboonsomsin, Real-World CO2 Impacts of Traffic Congestion, Transportation Research Record, 2008

2005.

South Asia Regional Conference of Transport and Logistic System, University of Moratuwa, August 2010.

Transport Research Forum, University of Moratuwa, July 2010. 